\title{
Thermally Agitated Self Assembled Carbon Nanotubes and the Scenario of Extrinsic Defects
}

\author{
Chernet Amente1, Keya Dharamvir ${ }^{2}$ \\ ${ }^{1}$ Physics Department, Addis Ababa Science and Technology University, Addis Ababa, Ethiopia \\ ${ }^{2}$ Physics Department, Panjab University, Chandigarh, India \\ Email: chernet.geffe@ambou.edu.et
}

Received 9 February 2015; accepted 25 February 2015; published 2 March 2015

Copyright (C 2015 by authors and Scientific Research Publishing Inc.

This work is licensed under the Creative Commons Attribution International License (CC BY).

http://creativecommons.org/licenses/by/4.0/

(c) (i) Open Access

\begin{abstract}
Employing the arc discharge method we prepared carbon nanotubes, CNTs, in open air deionized water. Their morphology was studied varying the annealing temperature and characterizing by Raman Spectroscopy, Transmission Electron Microscopy (TEM), X-Ray Diffractogram (XRD) and Energy Dispersion X-Ray (EDX). According to the study, the CNTs are found self-assembled where the graphene sheets and/or defects are observed sort out themselves with enhancement of temperature.
\end{abstract}

Keywords

Arc Discharge, Carbon Nanotubes, Defects, Self Assembling, Thermal Agitation

\section{Introduction}

Since their discovery [1] carbon nanotubes are a front line research topic. These of needle-like configurations, observed during intensive research work on fullerene C60,were found differently fascinated and known to have single, double and multi walled [1] [2] structures. Properties of these systems have been studied theoretically and experimentally for over decades. The theoretical method involved various techniques including simulations by means of different algorithms [3]. The experimental method, however, required sample preparation and characterization phenomenon [1] [2] [4] [5]. In a sample preparation arc discharge, Chemical Vapor Deposition (CVD) and Laser Ablation [6] methods have been utilized at most. Characterizations and typical analysis have been done by Raman Spectroscopy, X-Ray Diffiractometer (XRD), Transmission Electron Microscopy (TEM), 
Scanning Electron Microscopy (SEM), Atomic Force Microscopy (AFM), Energy Dispersion X-Ray (EDX), Scanning Tunneling Microscopy (STM), etc. depending on the type of the structure and morphology to be studied [7].

The quality and quantity of the nanotubes is understood as to depend on the type of the discharging method, annealing temperature and time, refluxing temperature and time, system geometry, the electric current and voltage applied, and type of acids used for the reflux [8]-[10]. In most cases samples are prepared from commercially available graphite rods, mounted on electrodes of the discharger and kept few millimeters of distances apart before driving one towards the other, in certain gas or liquid environment [1] [6] [9].

Following the realistic tight-binding band calculations by Hamada et al., 1992 [11], experimental and theoretical works have been reporting that these tubes can be either metals [12] or semiconductors [13] [14]. Electronic band structure calculations have also predicted that the $(n, m)$ indices determine the metallic or semiconducting behavior of CNTs [11] [15]. These nanotubes are understood as efficient sources of electron field emitters [16] [17] and enabled fabrication of remarkable varieties of field-effect transistors [18]-[20] for potential applications.

Studies indicate that, whether the product is single walled or multi walled depends on the amount of catalyst used [21]. Accordingly, the lesser the catalyst leads to multi walled carbon nanotubes production. This might result in the variation of sizes. Diameter of single walled carbon nanotubes (SWNTs) could vary up to $1.4 \mathrm{~nm}$ and millimeters of length [22], and that of multiwalled carbon nanotubes (MWNTs) up to hundreds of nanometers width [23] almost independent of the preparation temperature [24]. It has been reported that production of MWNTs by carbon arc discharge method does not require any catalyst. The remaining techniques, however, involved metal doping and resulted in producing lesser crystalline and many more defects [25].

In this research, we used the arc-discharge method and prepared carbon nanotubes in a deionized water. Structural analyses of the samples were done by spectra, diffraction and image pattern recording.

\section{The Experiment}

In sample preparation we used carbon graphite rods, of nearly $23 \mathrm{~cm}$ in length and $7.64 \mathrm{~mm}$ diameter, commercially available. These rods were cut into pieces and mounted on the electrodes of the arc used as anode and cathode, kept few millimeters apart in a chamber of deionized water cover, as shown in Figure 1, before the process.

A d.c. of 50 - 200 A driven by $40 \mathrm{~V}$ created a high temperature discharge between the two electrodes where high sparking and little smoke was observed. After frequent discharging the chamber is removed and the product soot along with water is transferred into a bigger beaker and kept covered with aluminum foil for about 6 hours until crude is formed at the bottom and then decanted. Subsequently, the crude is made open air dry at $100^{\circ} \mathrm{C}$ for about 12 hours and the dried soot is collected for technical analysis.

\section{Results and Discussion}

The crystal purity and defect concentration of the graphite powder was tested by the mechanism of Raman spectra recording at room temperature, using RENISHAW-Raman equipment operating with Argon laser of one excitation and wavelength $514 \mathrm{~nm}$.

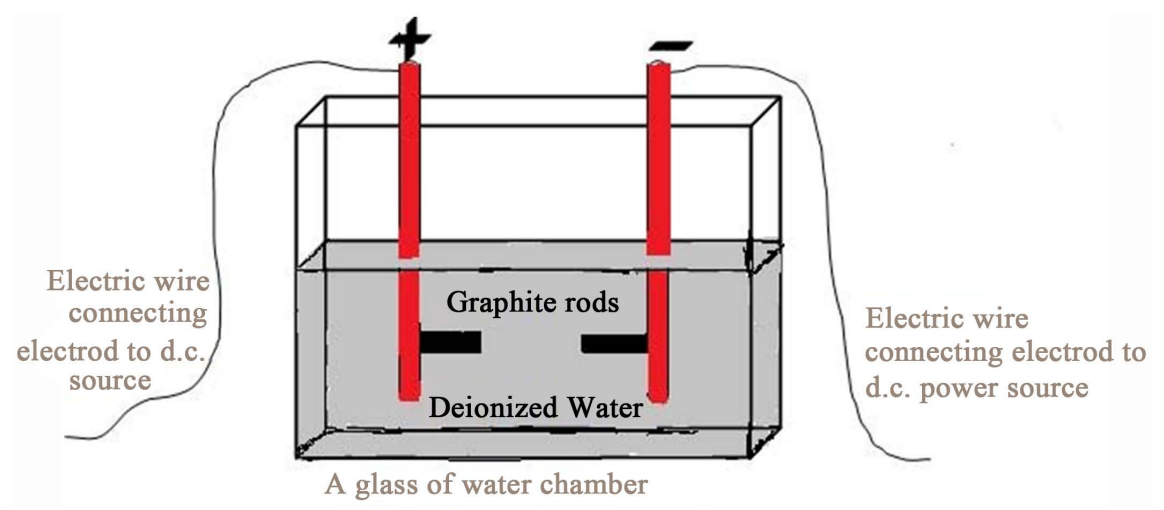

Figure 1. Schematic diagram of locally devised arcing equipment. 
The $I_{D} / I_{G}$ ratio indicated that the graphite used contains large amount of defects, as illustrated in Figure 2(a). The collected data plots in Figure 2(b) and Figure 2(c) show that there is D-band (disorder induced phonon mode [26]) at $1348 \mathrm{~cm}^{-1}$ and strong peak G (graphite)-band at $1583 \mathrm{~cm}^{-1}$ Raman shift for the as prepared sample and the D-band at $1349 \mathrm{~cm}^{-1}$ and the G-band at $1582 \mathrm{~cm}^{-1}$ for the annealed sample, respectively. Further analysis indicates that there is a G-peak due to a high production of monolayer graphene [27] at $2710 \mathrm{~cm}^{-1}$. The increase in $\mathrm{I}_{\mathrm{D}} / \mathrm{I}_{\mathrm{G}}$ is, therefore, because of that annealing successfully altered the CNTs, perhaps, increasing the number of defects on their side walls [28]. The increase in D-band frequency might be due to the chemical charge transfer under different temperature treatment and/or amorphous carbon content most likely from the destruction of the CNTs [29]. The D-band $\left(\mathrm{sp}^{3}\right)$ is attributed as associated with vibrations of carbon atoms with dangling bonds in the terminal plane of disordered carbon/impurities whereas the G-band is related to the vibration of $\mathrm{sp}^{2}$ bonded carbon atoms in a two-dimensional hexagonal lattice [30]. Figure 2(c) shows that there are D'-band peaks at $1614 \mathrm{~cm}^{-1}$ and $1629 \mathrm{~cm}^{-1}$ indicating the presence of randomly distributed impurities or surface charges in the graphene, resulting in splitting of the G-band in to G and D'-peaks. Further scrutiny shows that there is a G'band (the second strongest after the G mode and the second overtone of the defect-induced D mode) at about $2708 \mathrm{~cm}^{-1}$ and attributed as useful in determining the number of graphene layers [31].

The X-Ray Diffractometer (XRD) D8 advanced, from Bruker A $\times$ S, of scan type locked coupled, scan angle $20^{\circ}-80^{\circ}$ range, scan step $0.02^{\circ}$, scan speed $3^{\circ} / \mathrm{min}$, max. power $40 \mathrm{kV} / 40 \mathrm{~mA}$, Cu tube, T/T horizontal, for which scan time is about 20 minutes for each sample and wavelength $1.5406 \mathrm{~A}^{\circ}$ is used to identify the composition of the samples.

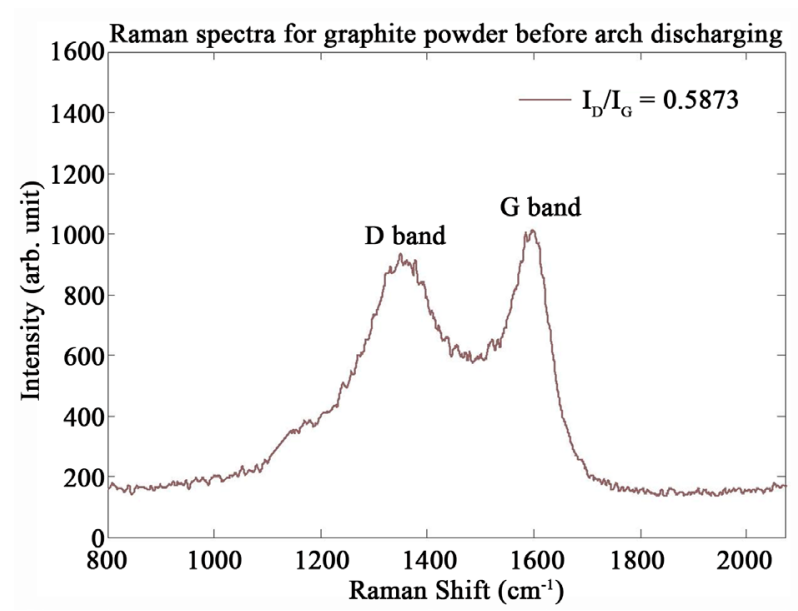

(a)

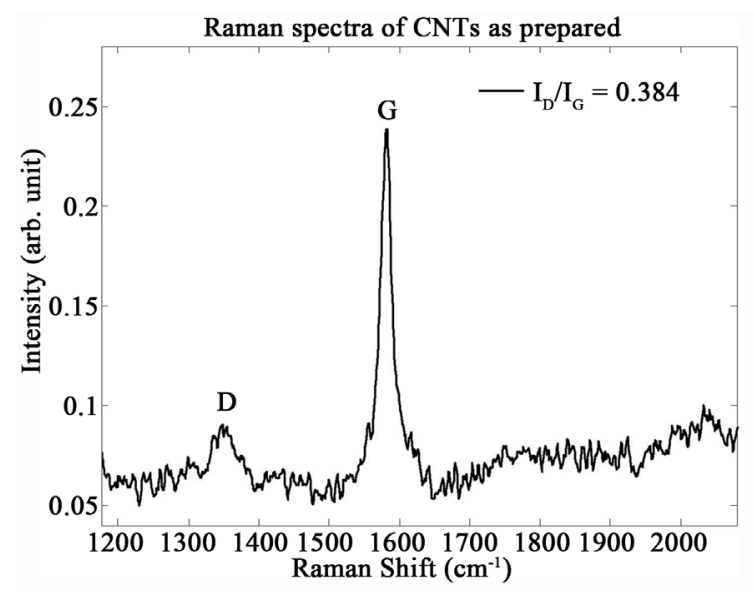

(b)

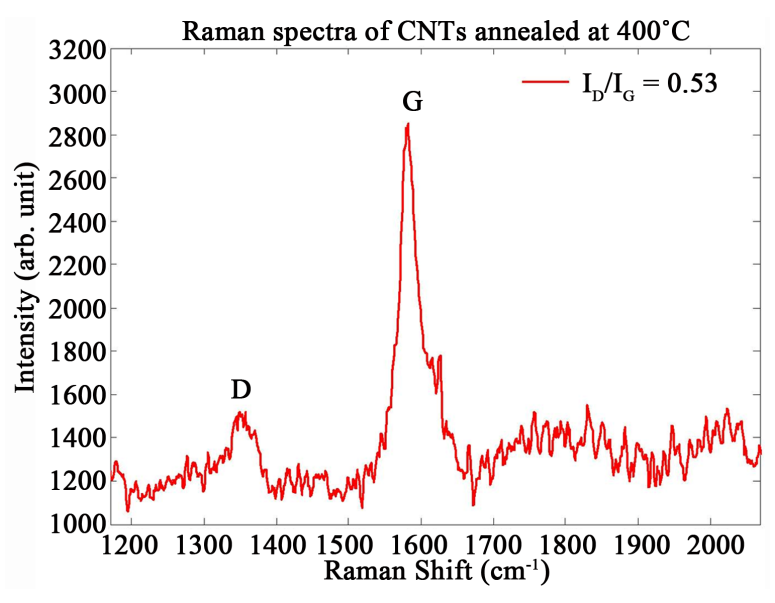

(c)

Figure 2. Raman spectra (a) of graphite powder before arc discharge (b) for the as prepared CNTs and (c) for CNTs annealed at $400^{\circ} \mathrm{C}$ for 30 minutes. 
Accordingly, the peaks at about $26^{\circ}, 44^{\circ}$, and $76^{\circ}$ shown in Figure 3 corresponds to indices of graphite $\mathrm{C}(002), \mathrm{C}(101)$ and $\mathrm{C}(110)$ planes, respectively, indicating the presence of CNTs in the sample and the scattering of incident beam by (002) faces [32] which always exists, as far as X-ray diffraction pattern of CNT's are close to that of graphite [33], in agreement with experimental results obtained earlier and JCPDF \#751621 indications [34].

The analysis was repeated, using another diffractometer, model name X'Pert PRO, company name PANalytical (formerly known as Philips) with scan type continues, scan angle $10^{\circ}-90^{\circ}$, step size $10,167 /$ degree, time for step 20 sec, by $\mathrm{CuK} \alpha_{1}$ laser radiation, scan speed $0.1^{\circ}$ sec, $\lambda=1.540598 \mathrm{~A}^{\circ}$ wavelength, generator power setting $40 \mathrm{kV}$, and current of $40 \mathrm{~mA}$, for conformation.

The data plot of the result, shown in Figure 4(b), also suggests that the reoccurrence of the peaks would come from the defects found in the raw material as far as reappeared in the unprocessed graphite powder, at about $28.2^{\circ}$ for instance, and revealed by broadened line width at about $25.77^{\circ}$ for graphite as well (see Figure 4(a)).

The EDX analysis indicates that there are Calcium (Ca) and Oxygen (O) constituents in the samples, perhaps, introduced during industrial preparation of graphite rod, as shown in Figure 5, and are known as introducing extra peaks at about $28^{\circ}, 47^{\circ}$, and $56^{\circ}$, and could not be removed by annealing. Cu peaks are due to grip on which the sample was deposited for analysis.

Scherrer's formula [35] $t=\mathrm{k} \lambda / \beta \cos \theta_{\mathrm{B}}$ which is derived from Bragg's equation that has been utilized in determining crystallite inter planar spacing, is employed in estimating the nanotubes thickness $t$, where $\kappa$ is the shape factor approximated to $0.9, \beta=\Delta 2 \theta \times \pi / 180^{\circ}$ is the line broadening at half the maximum intensity (at full width half of maximum intensity, FWHM), $\lambda$ is the X-ray wave length and $\theta_{\mathrm{B}}$ is the Bragg's angle.

One can understand, from Table 1 , that the diffraction peaks at $2 \theta$ are slightly shifted as a result of further annealing (Figure 3(c)) perhaps due to formation of CNTs whose production has been overwhelmed by the defects. Moreover, the increase in thickness can be due to self-assembling of the CNTs.

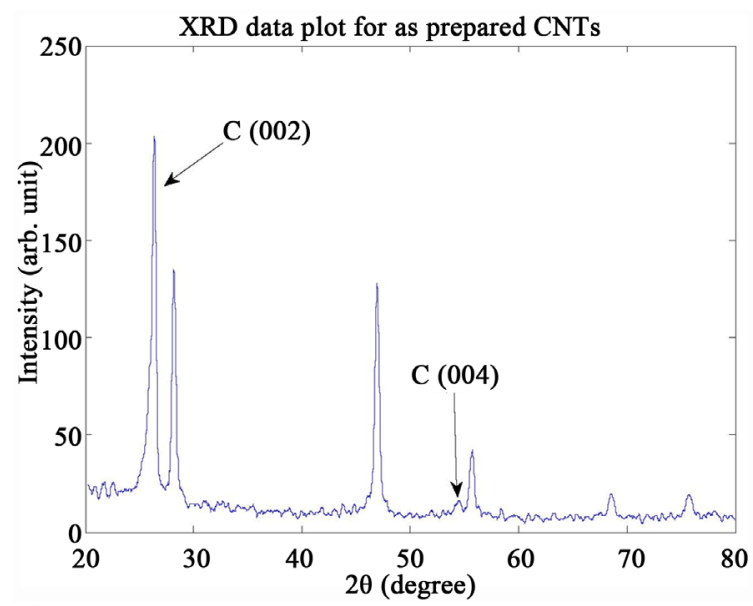

(a)

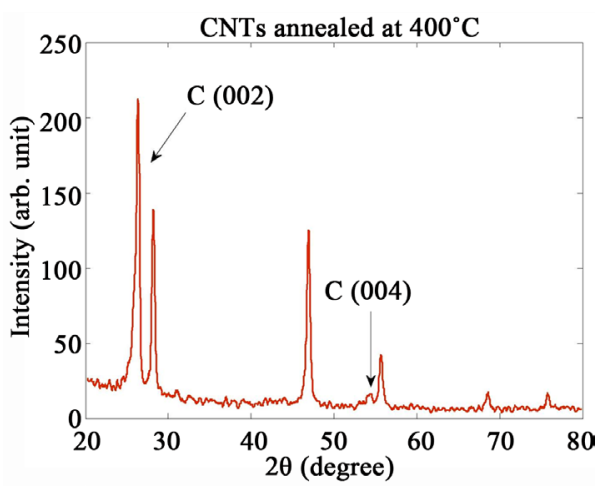

(b)

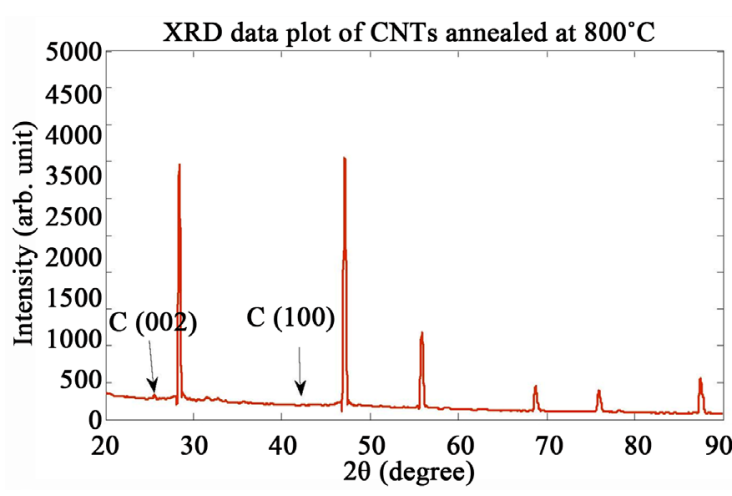

(c)

Figure 3. XRD profile of (a) the as prepared CNTs (b) CNTs annealed at $400^{\circ} \mathrm{C}$ and (c) CNTs annealed at $800^{\circ} \mathrm{C}$. 


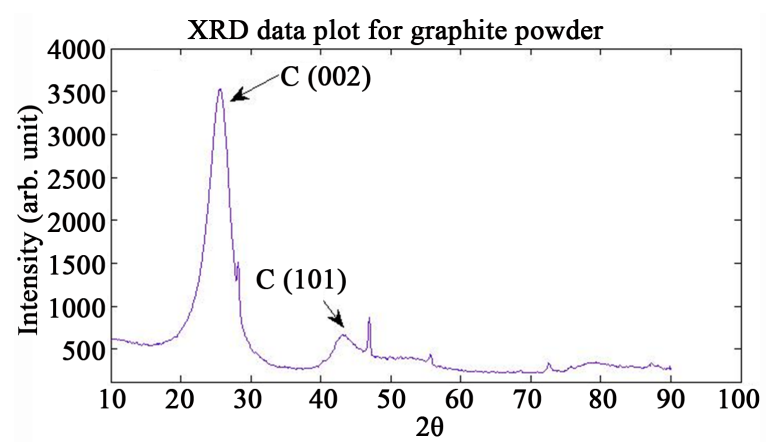

(a)

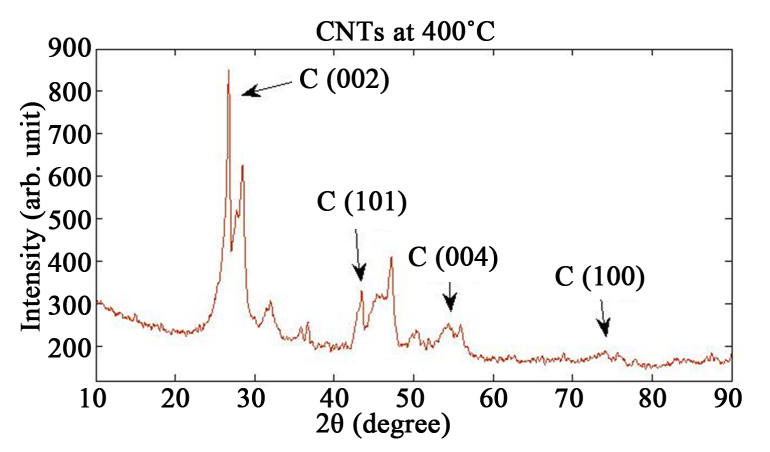

(b)

Figure 4. XRD profile of (a) Graphite powder (b) CNTs annealed at $400^{\circ} \mathrm{C}$ for comparison.

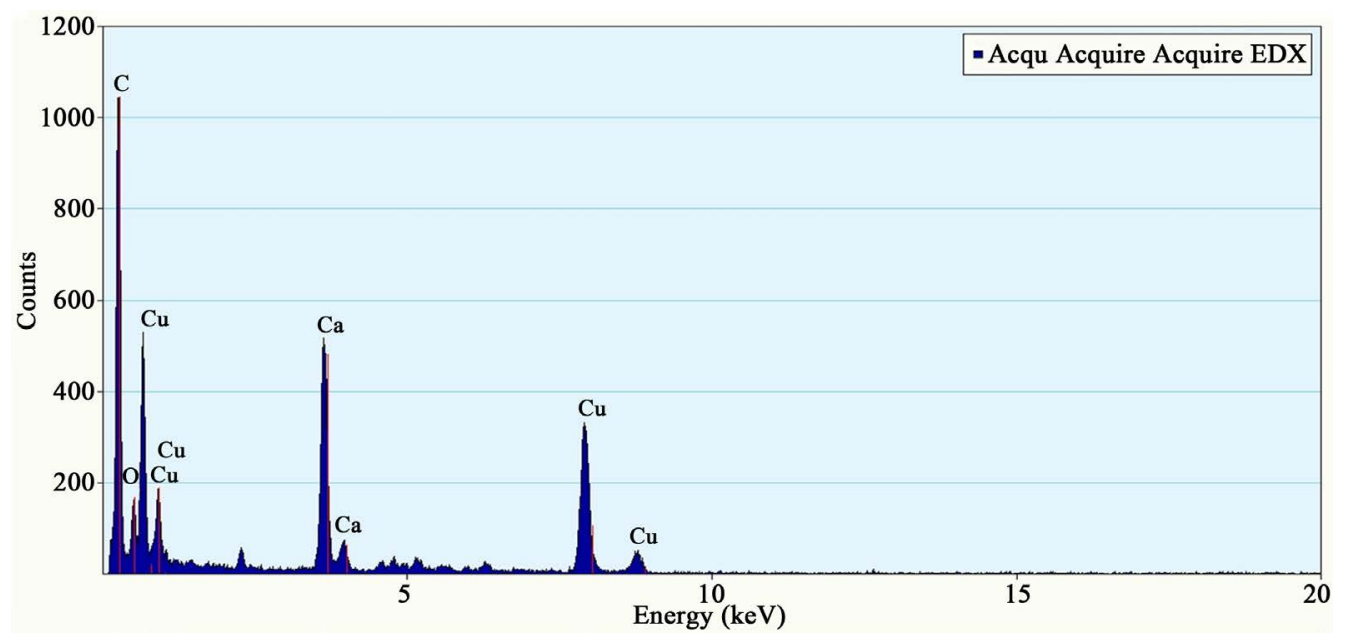

Figure 5. EDX pattern showing contents of the samples without metal doping.

Table 1. The XRD data of graphite powder and carbon nanotubes pre and post annealing referring to Figure 3 and Figure 4.

\begin{tabular}{|c|c|c|c|c|}
\hline & Graphite sample & Pristine CNTs & At $400^{\circ} \mathrm{C}$ & At $800^{\circ} \mathrm{C}$ \\
\hline $2 \theta$ (deg.) & 25.63 & 26.28 & 26.79 & 25.58 \\
\hline$\Delta 2 \theta$ (deg.) & 3.52733 & 0.95916 & 1.01797 & 0.19841 \\
\hline$t\left(A^{\circ}\right)$ & 23.0881 & 85.0181 & 80.1906 & 410.4199 \\
\hline
\end{tabular}

Table 2 shows that sizes of the attributed defects could decrease with increase in the Bragg's angle at $800^{\circ} \mathrm{C}$ annealing. However, there are no well defined circumstances in the case of the pristine and the $400^{\circ} \mathrm{C}$ annealed samples. It is worth mentioning that the size of those defects in the unprocessed graphite sample at about $28.2^{\circ}$ is nearly $33.886 \mathrm{~A}^{\circ}$. This indicates that size of the defects has increased due to thermal agitation and perhaps burning of some of the CNTs which are known to self categorize as also shown in Figure 8.

Images of the CNTs were collected using transmission electron microscopy (TEM) model 7500, $2 \mathrm{keV}$ HITACHI, maximum magnification $6 \times 10^{6}$ times and resolution $0.2 \mathrm{~A}^{\circ}$, after sonication of the nanopowder suspending in ethanol and exposing to ultrasonic waves for $3 \mathrm{hr}$. As shown in Figure 6, the as prepared sample has contained puffy colored impurities stacked on the surface of the tubes and also scattered elsewhere. After open air annealing at $400^{\circ} \mathrm{C}$ the density of these impurities and/or amorphous carbon [10] is reduced and the clarity of the CNTs is improved, as in Figure 7. This shows that further annealing to certain temperature limit may give better and more purified CNT products. The measured internal diameter of these tubes is known to vary nearly from $1.0 \mathrm{~nm}-7.0 \mathrm{~nm}$ and the external diameter ranges between $6 \mathrm{~nm}-26 \mathrm{~nm}$, where their length extends to about $0.4 \mu \mathrm{m}$.

We have also further annealed the CNTs at $800^{\circ} \mathrm{C}$ for 30 minutes and cooled back to room temperature. The color feature of the sample powder was found changed to grey and reduced in quantity, in agreement with pre- 

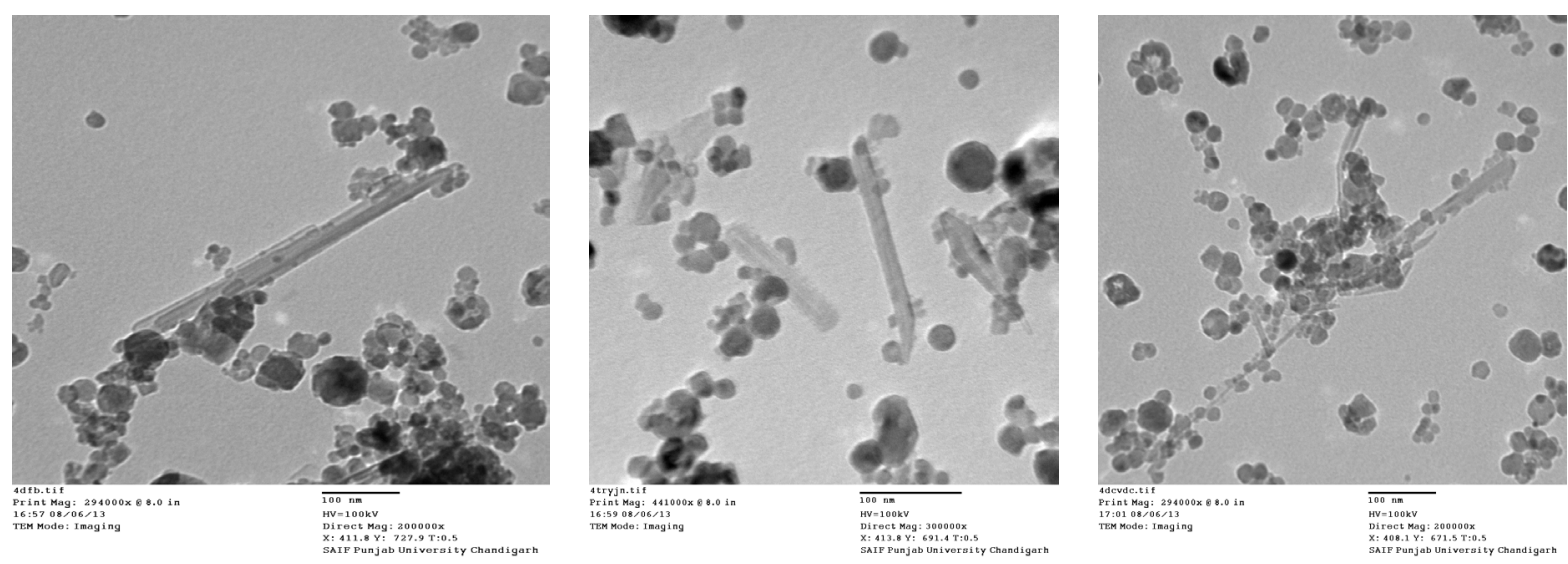

Figure 6. TEM images of the as prepared CNTS from different points of focus.
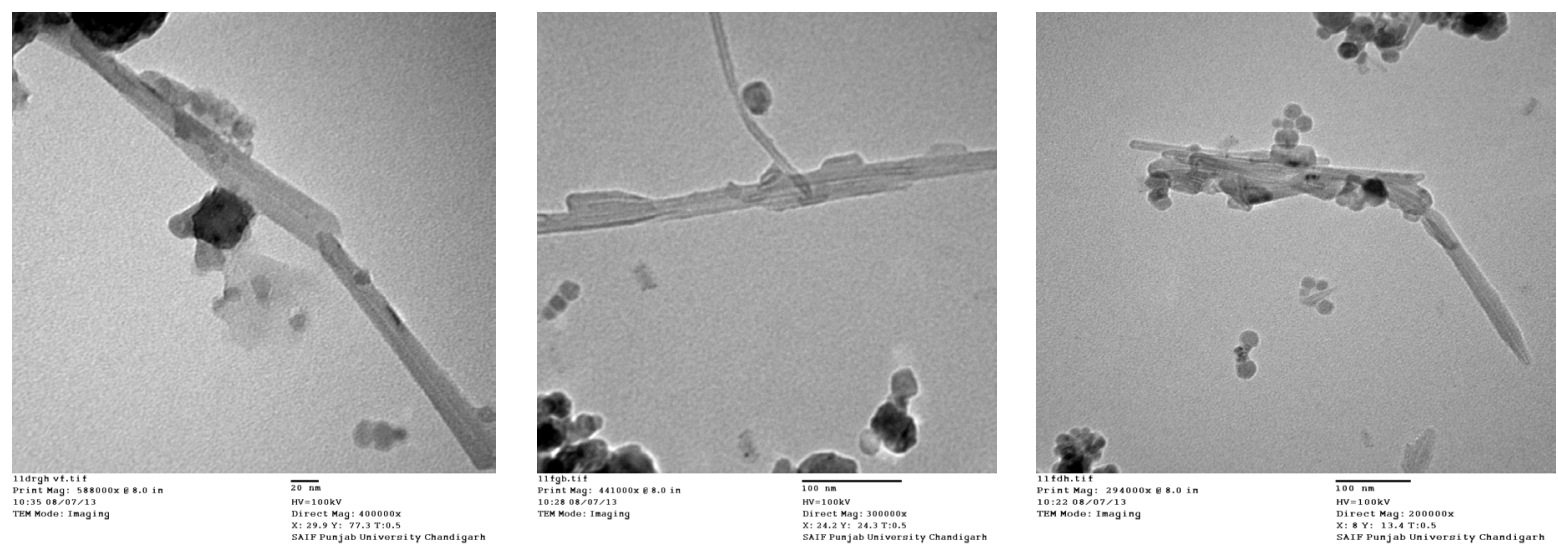

Figure 7. TEM images of CNTs post annealing at $400^{\circ} \mathrm{C}$ for 30 minutes, collected from different points of focus.

Table 2. Calculated thickness (particle size, t) of impurities from XRD data pre and post annealing, referring to Figure 3, and applying the Scherrer's formula.

\begin{tabular}{|c|c|c|c|c|c|}
\hline \multicolumn{6}{|c|}{ For the as Prepared CNTs } \\
\hline $2 \theta$ (deg.) & 28.136 & 46.936 & 55.617 & 68.198 & 76.128 \\
\hline$\Delta 2 \theta$ (deg.) & 1.46519 & 0.55271 & 2.34239 & 7.04736 & 4.95001 \\
\hline$t\left(A^{\circ}\right)$ & 55.8742 & 156.6317 & 38.3281 & 13.6078 & 20.3761 \\
\hline \multicolumn{6}{|c|}{ For CNTs annealed at $400^{\circ} \mathrm{C}$} \\
\hline $2 \theta$ (deg.) & 28.16245 & 46.93296 & 55.66761 & 68.48652 & 75.96305 \\
\hline$\Delta 2 \theta$ (deg.) & 1.18242 & 0.55498 & 1.38371 & 4.72368 & 4.95001 \\
\hline$t\left(A^{\circ}\right)$ & 69.2402 & 155.9893 & 64.8982 & 20.3364 & 20.3761 \\
\hline \multicolumn{6}{|c|}{ For CNTs annealed at $800^{\circ} \mathrm{C}$} \\
\hline $2 \theta$ (deg.) & 28.36802 & 47.09762 & 55.68 & 68.76009 & 75.96692 \\
\hline$\Delta 2 \theta$ (deg.) & 0.16689 & 0.19188 & 0.33996 & 0.72157 & 2.51296 \\
\hline$t\left(A^{\circ}\right)$ & 490.7903 & 151.4543 & 264.3844 & 133.3474 & 40.0926 \\
\hline
\end{tabular}


viously obtained results [25]. According to the TEM images the CNTs are extremely clean and condensed in comparison to the lower temperature annealed samples shown in Figure 6 and Figure 7. There were large amounts of heavy sheets of graphene layers, amorphous carbon and/or other impurities and perhaps broken CNTs produced, as seen in Figures 8(b)-8(d). These implies that some of the CNTs might have burned and are unstable at higher temperatures [36], suggesting reduction of the annealing temperature and/or time could resolve the scenario of obtaining high yield. Moreover, the amount of impurities scattered around the CNTs shown in Figure 6 are known to decrease with further annealing and the CNTs are progressively freed from those surface bonded agents. These CNTs are found in bundle rather than scattered as the graphene layers and/or amorphous carbon does as well. An interesting feature is, therefore, the separation of the system into different category. The CNTs bundled as in Figure 8(a); graphene sheets of edge thickness about $20 \mathrm{~nm}$ forced to be arranged in

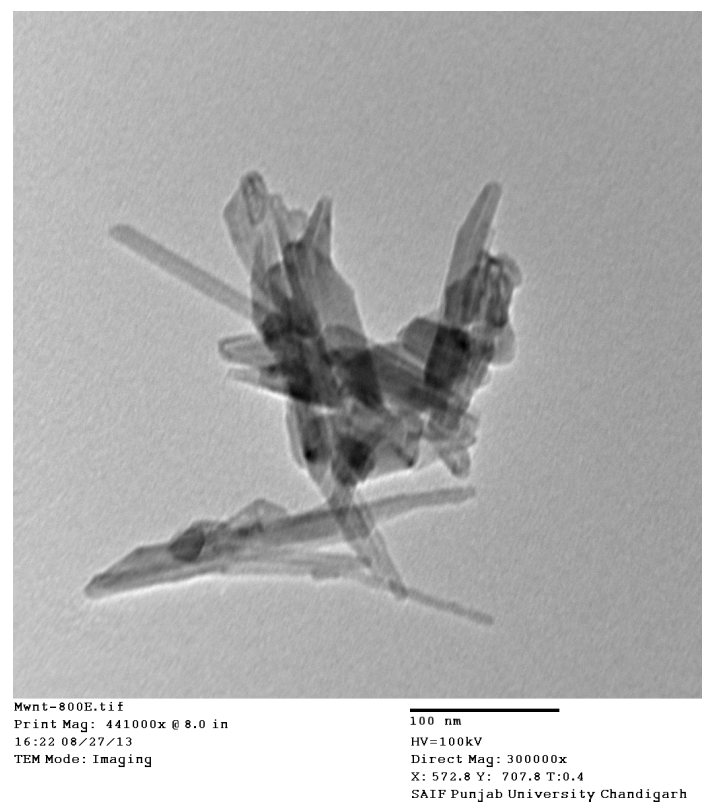

(a)

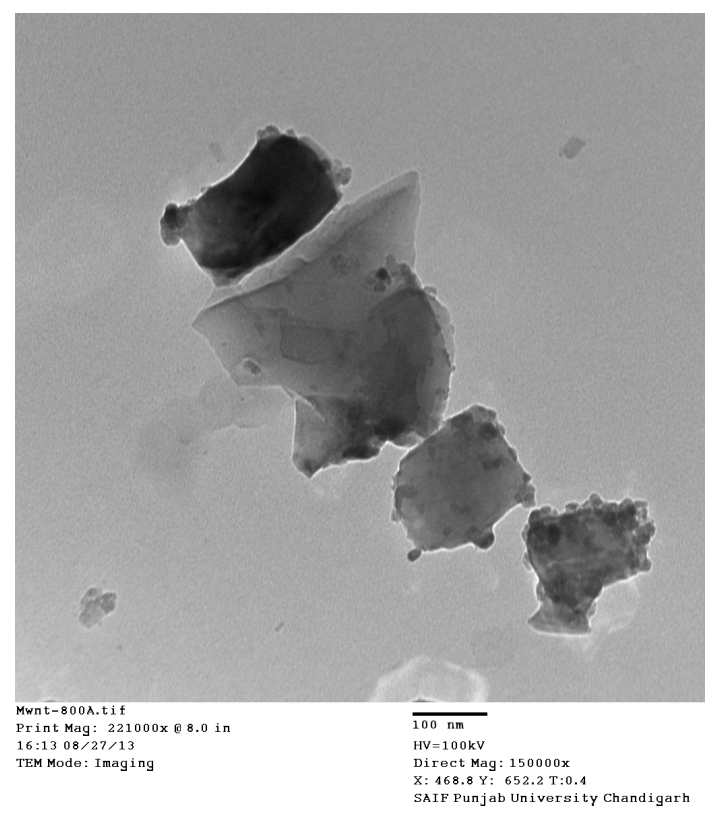

(c)

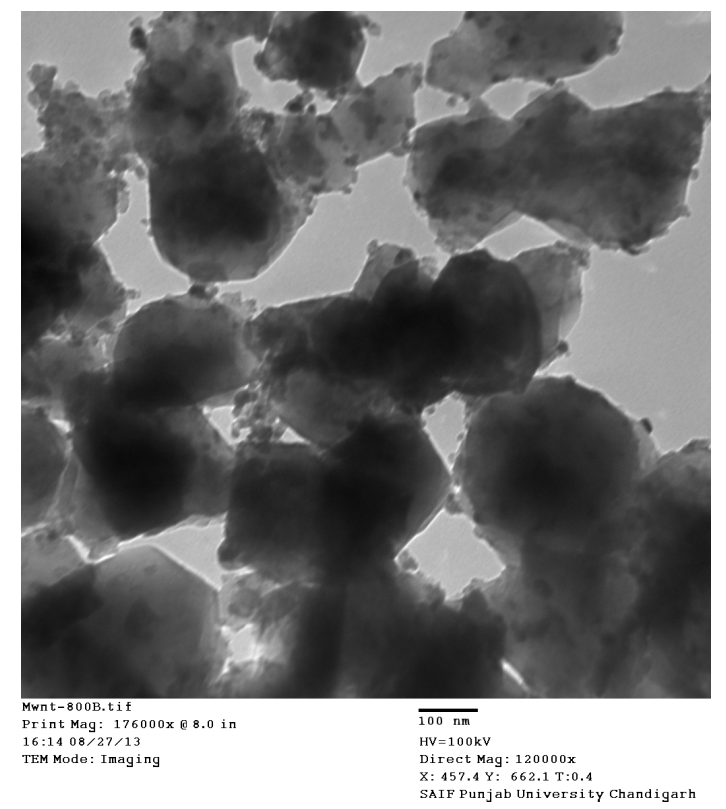

(b)

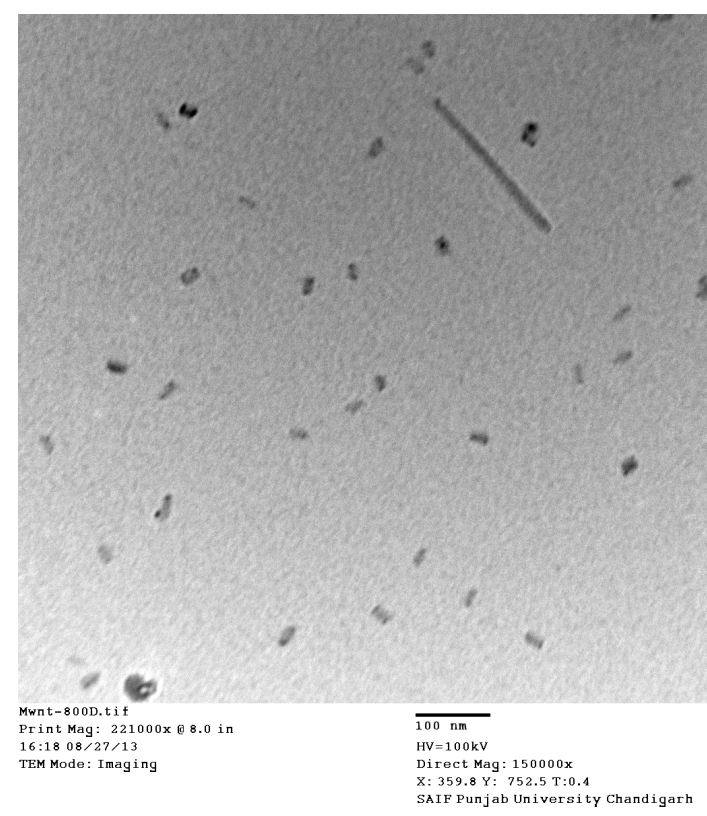

(d)

Figure 8. TEM images CNTs post annealing at $800^{\circ} \mathrm{C}$ for 30 minutes. 
order, as in Figure 8(b); micron sized amorphous system gathered and attached to one another as in Figure 8(c); and black spotted objects, thought as broken CNTs, of size $5 \mathrm{~nm}-30 \mathrm{~nm}$ in different category as in Figure 8(d). These indicate that during further annealing structures of the same category get sorted and move to one side assisting enhancement of the purification process.

\section{Conclusion}

The prepared and purified CNTs in a deionized water environment are understood to have the same feature as those prepared in $\mathrm{N}_{2}, \mathrm{H}_{2}$, He or their mixture. The challenging scenario was finding the source of extra peaks observed during XRD analysis, which could have been resolved by EDX analysis that clearly shown that Ca, O and/or their compound existed in the sample. According to the TEM images, the CNTs are identified as to selfassemble further being thermally agitated with increase in temperature. The increase in $\mathrm{I}_{\mathrm{D}} / \mathrm{I}_{\mathrm{G}}$ ratio can be attributed as indicator for structural defects due to annealing the CNTs and presence of impurities. It is also understood that elemental analysis should be done for the contents of the sample source (graphene) prior to any course of action in order to easily manage experimental procedures and fix treatment technique for the removal of defects. Finally, the water environment preparation of CNTs is understood as the most cost effective mechanism relative to those has been in use. Thermal agitation is also known to self-categorizing constituents in the sample; signifying complete removal of defects requires additional treatment technique.

\section{Acknowledgements}

We acknowledge the financial support from the C. V. Raman fellow ship for African researchers and Mr. Charanjit Singh, department of chemistry Panjab University, for his invaluable assistance.

\section{References}

[1] Iijima, S. (1991) Helical Microtubules of Graphitic Carbon. Nature, 354, 56-58. http://dx.doi.org/10.1038/354056a0

[2] Iijima, S. and Ichihashi, T. (1993) Single-Shell Nanotubes of 1-nm Diameter. Nature, 363, 603-605. http://dx.doi.org/10.1038/363603a0

[3] Feng, D. (2005) Theoretical Study of the Stability of Defects in Single-Walled Carbon Nanotubes as a Function of Their Distance from the Nanotube End. Physical Review B, 72, 1-7.

[4] Bethune, D.S., Kiang, C.H., de Vries, M.S., Gorman, G., Savoy, R., Vasques, J. and Beyers, R. (1993) Cobalt-Catalyzed Growth of Carbon Nanotubes with Single-Atomic-Layer Walls. Nature, 363, 605-607. http://dx.doi.org/10.1038/363605a0

[5] Yuhuang, W., Myung, J.K., Hongwei, S., Carter, K., Hua, F., Lars, M.E., Wen-Fang, H., Sivaram, A., Robert, H.H. and Richard, E.S. (2005) Continued Growth of Single-Walled Carbon Nanotubes. Nano Letters, 5, 997-1002. http://dx.doi.org/10.1021/nl047851f

[6] Journet, C. and Bernier, P. (1998) Production of Carbon Nanotubes. Applied Physics A, 67, 1-9. http://dx.doi.org/10.1007/s003390050731

[7] Bellucci, S., Gaggiotti, G., Marchetti, M., Micciulla, F., Mucciato, R. and Regi, M. (2007) Atomic Force Microscopy Characterization of Carbon Nanotubes. Journal of Physics: Conference Series, 61, 99-104.

[8] Yoshinori, A., Xinluo, Z., Sakae, I. and Iijimaa, S. (2002) Mass Production of Multiwalled Carbon Nanotubes by Hydrogen Arc Discharge. Journal of Crystal Growth, 237-239, 1926-1930. http://dx.doi.org/10.1016/S0022-0248(01)02248-5

[9] Shi, Z., Lian, Y., Zhou, X., Gu, Z., Zhang, Y., Iijima, S., Zhou, L., Yue, T.K. and Zhang, S. (1999) Mass Production of Single- Wall Carbon Nanotubes by Arc Discharge Method. Carbon, 37, 1449-1453. http://dx.doi.org/10.1016/S0008-6223(99)00007-X

[10] Stancu, M., Ruxanda, G., Ciuparu, D. and Dinescu, A. (2011) Purification of Multiwall Carbon Nanotubes Obtained by AC Arc Discharge Method. Optoelectronics and Advanced Materials, R5, 846-850.

[11] Hamada, N., Sawada, S. and Oshiyama, A. (1992) New One-Dimensional Conductors: Graphitic Microtubules. Physical Review Letters, 68, 1579-1581. http://dx.doi.org/10.1103/PhysRevLett.68.1579

[12] Tans, S.J., Devoret, M.H., Dai, H., Thess, A., Smalley, R.E., Georliga, L.J. and Dekker, C. (1997) Individual SingleWall Carbon Nanotubes as Quantum Wires. Nature, 386, 474-477. http://dx.doi.org/10.1038/386474a0

[13] Tans, S.J., Verschueren, R.M. and Dekker, C. (1998) Room Temperature Transistor Based on a Single Carbon Nanotube. Nature, 393, 49-52. http://dx.doi.org/10.1038/29954 
[14] McEuen, P.L., Fuhrer, M.S. and Park, H. (2002) Single-Walled Carbon Nanotube Electronics. IEEE Transitions on Nanotechnology, 1, 78-85. http://dx.doi.org/10.1109/TNANO.2002.1005429

[15] Garau, C., Frontera, A., Quinonero, D., Costa, A., Ballester, P. and Dey, P.M. (2003) Lithium Diffusion in Single-Walled Carbon Nanotubes: A Theoretical Study. Chemical Physics Letters, 374, 548-555. http://dx.doi.org/10.1016/S0009-2614(03)00748-6

[16] de Heer, W.A., Chatelain, A. and Ugarte, D. (1995) A Carbon Nanotube Field-Emission Electron Source. Science, 270, 1179-1180. http://dx.doi.org/10.1126/science.270.5239.1179

[17] Jensen, A., Hauptmann, J.R., Nygård, J., Sadowski, J. and Lindelof, P.E. (2004) Hybrid Devices from Single Wall Carbon Nanotubes Epitaxially Grown into a Semiconductor Heterostructure. Nano Letters, 4, 349-352. http://dx.doi.org/10.1021/nl0350027

[18] Martel, R., Schmidt, T., Shea, H.R., Hertel, T. and Avouris, P. (1998) Single- and Multi-Wall Carbon Nanotube FieldEffect Transistors. Applied Physics Letters, 73, 2447-2449. http://dx.doi.org/10.1063/1.122477

[19] Tans, S.J., Verschueren, A.R.M. and Dekker, C. (1998) Room-Temperature Transistor Based on a Single Carbon Nanotube. Nature, 393, 49-52. http://dx.doi.org/10.1038/29954

[20] Alexander, A.K., Sergey, B. Lee, M.Z., Baughman, R.H. and Zakhidov, A.A. (2010) Electron Field Emission from Transparent Multiwalled Carbon Nanotube Sheets for Inverted Field Emission Displays. Carbon, 48, 41-46. http://dx.doi.org/10.1016/j.carbon.2009.08.009

[21] Chai, S.P., Zein, S.H.S. and Mohamed, A.R. (2004) A Review on Carbon Nanotubes Production via Catalytic Methane Decomposition. 1st National Postgraduate Colloquium School of Chemical Engineering USM NAPCOl, 60-69.

[22] Huang, S., Cai, X. and Liu, J. (2003) Growth of Millimeter-Long and Horizontally Aligned Single-Walled Carbon Nanotubes on Flat Substrates. Journal of the American Chemical Society, 125, 5636-5637. http://dx.doi.org/10.1021/ja034475c

[23] Zhang, H., Fu, X., Yin, J., Zhou, C., Chen, Y., Li, M. and Wei, A. (2005) The Effects of MWNTs with Different Diameters on the Electrochemical Hydrogen Storage Capability. Physics Letters A, 339, 370-377. http://dx.doi.org/10.1016/j.physleta.2005.03.013

[24] Mahanandia, P., Schneider, J.J., Engel, M., Stühn, B., Subramanyam, S.V. and Nanda, K.K. (2011) Studies towards Synthesis, Evolution and Alignment Characteristics of Dense, Millimeter Long Multiwalled Carbon Nanotube Arrays, Beilstein. Journal of Nanotechnology, 2, 293-301. http://dx.doi.org/10.3762/bjnano.2.34

[25] Grobert, N. (2007) Carbon Nanotubes Becoming Clean. Materials Today, 10, 28-35. http://dx.doi.org/10.1016/S1369-7021(06)71789-8

[26] Zhao, X. and Ando, Y. (1998) Raman Spectra and X-Ray Diffraction Patterns of Carbon Nanotubes Prepared by Hydrogen Arc Discharge. Japanese Journal of Applied Physics, 37, 4846-4849.

[27] Iqbal, M.W., Singh, A.K., Iqbal, M.Z. and Eom, J. (2012) Raman Fingerprint of Doping Due to Metal Adsorbates on Graphene. Journal of Physics Condensed Matter, 24, Article ID: 335301.

[28] Jeong, Y., Kim, J. and Lee, G.W. (2010) Optimizing Functionalization of Multiwalled Carbon Nanotubes Using Sodium Lignosulfonate. Colloid and Polymer Science, 288, 1-6. http://dx.doi.org/10.1007/s00396-009-2127-8

[29] Dresselhaus, M.S., Rao, A.M. and Dresselhaus, G. (2004) Raman Spectroscopy in Carbon Nanotubes. Encyclopedia of Nanoscience and Nanotechnology, 9, 307-338.

[30] Li, H., He, X., Kang, Z., Huang, H., Liu, Y., Liu, J., Lian, S., Tsang, C.H.A., Yang, X. and Lee, S.-T. (2010) WaterSoluble Fluorescent Carbon Quantum Dots and Photocatalyst Design. Angewandte Chemie International Edition, 49, 4430-4434.

[31] Akhavan, O. (2011) Photocatalytic Reduction of Graphene Oxides Hybridized by ZnO Nanoparticles in Ethanol. Carbon, 49, 11-18. http://dx.doi.org/10.1016/j.carbon.2010.08.030

[32] Caoa, A., Xua, C., Lianga, J., Wu, D. and Wei, B. (2001) X-Ray Diffraction Characterization on the Alignment Degree of Carbon Nanotubes. Chemical Physics Letters, 344, 13-17. http://dx.doi.org/10.1016/S0009-2614(01)00671-6

[33] Khani, H. and Moradi, O. (2013) Influence of Surface Oxidation on the Morphological and Crystallographic Structure of Multi-Walled Carbon Nanotubes via Different Oxidants. Journal of Nanostructure in Chemistry, 3, 73.

[34] Wang, Z., Ba, D., Liu, F., Cao, P., Yang, T., Gu, Y. and Gao, H. (2005) Synthesis and Characterization of Large Area WellAligned Carbon Nanotubes by ECR-CVD without Substrate Bias. Vacuum, 77, 139-144. http://dx.doi.org/10.1016/j.vacuum.2004.08.012

[35] Scherrer, P. (1918) Bestimmung der Größe und der innerenStruktur von Kolloidteilchen Mittels Röntgenstrahlen. P, Nachrichten von der Gesellschaft der Wissenschaften, Gttingen. Mathematisch-Physikalische Klasse, 2, 98-100.

[36] Ajayan, P.M. (1999) Nanotubes from Carbon. Chemical Reviews, 99, 1787-1799. http://dx.doi.org/10.1021/cr970102g 